\title{
Effect of Polyaniline Polymers with Boric Acid and Multi-Walled Carbon Nanotube on Dye Sensitive Solar Cells Performance
}

\author{
R. TAŞ* \\ Bartin University, Faculty of Science, Department of Biotechnology, 74100 Bartin, Turkey
}

Received: 22.01.2021 \& Accepted: 24.03.2021

Doi: 10.12693/APhysPolA.139.687

*e-mail: rtas@bartin.edu.tr

\begin{abstract}
In this study, polyaniline: boric acid/carbon nanotube (PANI-BA)/MWCNT conductive polymers were chemically synthesized by the oxidative polymerization method using $\mathrm{H}_{5} \mathrm{IO}_{6}$ (periodic acid) as the initiator. PANI-BA conductive polymers were synthesized for a 1:1 $\mathrm{H}_{5} \mathrm{IO}_{6}$ /aniline molar ratio. During the synthesis, $5 \%, 10 \%$, and $15 \%$ MWCNT were added to the medium at various weight percentages, respectively. Results were compared with MWCNT-doped and undoped polymer. Structural properties of the conducting polymers were characterized by the XRD, SEM, and DC conductivity measurements. For the first time, their applications as a counter electrode (CE) in dye-sensitized solar cells (DSSCs) were examined. The photovoltaic performance of DSSCs was evaluated by the current density-voltage $(\mathrm{J}-\mathrm{V})$ and external quantum efficiency measurements. The obtained photovoltaic results indicate that the ideal additive ratio is $10 \%$ MWCNT when compared with pure PB. Then, the current density increases from $3.47 \mathrm{~mA} / \mathrm{cm}^{2}$ to $4.91 \mathrm{~mA} / \mathrm{cm}^{2}$ with this additive rate as well as the power conversion efficiency of the batteries. It was determined that the efficiency reaches the maximal value of $1.15 \%$ from $0.69 \%$. These results showed that the doping of ideal MWCNT ratio in DSSCs is an effective way to increase the conversion efficiency of DSSCs.
\end{abstract}

topics: DSSCs, PANI, boric acid, MWCNT, solar cells efficiency

\section{Introduction}

Among the conductive polymers, polyaniline (PANI) is one of the most studied polymers due to its superior properties. Polyaniline has a wide range of applications such as rechargeable batteries [1], membranes [2-4], anti-corrosion coatings [5, 6], electronic circuits, as well as gas [7-9], $\mathrm{pH}[10]$, enzyme [11] and DNA sensors [12, 13]. Its easy chemical and electrochemical synthesis, its commercially inexpensive, easy conductivity control, and environmental stability make polyaniline a polymer incessantly attracting great interest [14].

The conductivity of the conjugated polymers is achieved by chemical oxidation or reduction reactions using several simple anionic or cationic species, called dopants [15]. Additives can be added directly to these polymers to change the transport, optical and mechanical properties of conductive polymers $[16,17]$. Among the doping agents, boric acid (BA) has been used for boron doping in many studies. Sevinis et al. [18] showed that the bandwidth values increased to $2.46-3.21 \mathrm{eV}$ and 2.18-2.88 eV, due to the intermolecular load transfer between dithienothiophenes units and boron receivers. Yağclet al. [19] synthesized a boric aciddoped poly (3,4-ethylene dioxythiophene): poly (styrene sulfonate) (PEDOT:PSS) polymers, and their effects on solar cell-based organic molecules were investigated. The results showed that the fill factor $(\mathrm{FF})$ and open-circuit voltage $\left(V_{\mathrm{oc}}\right)$ values increase the penetration value of the BA dopant layers of the PEDOT:PSS polymers [19]. Wu et al. [20] synthesized boron- and urea (nitrogen)doped monolayer graphene. The results showed that the doping of graphene with nitrogen and boron caused an increase in the electrical and optical performance of graphene sheets.

One should note that PANI is the only conducting polymer whose properties not only depend on the oxidation state but also on its protonation doping level and the nature of dopants [21]. These properties make PANI a promising candidate for the fundamental study of potential device applications, i.e., solar cells, light-emitting diodes, transparent electrodes, gas and humidity sensing, and many more in nanotechnology applications [22-24]. Regardless of the great potential of PANI, it has serious disadvantages such as its insolubility in many solvents and poor processing ability. Attempts have been made for many years to change its resolution. The most widely accepted example of this was mixing PANI with organic acids such as dodecyl benzene sulfonic acid (DBSA) [25, 26]. 
Coding and conductivity of MWCNT-doped and undoped polyaniline samples synthesized.

TABLE I

\begin{tabular}{l|l|c|c|c|c}
\hline \hline Code & \multicolumn{1}{|c|}{ Common name } & Aniline & Boric acid & Polyaniline-BA/MWCNTs & $\begin{array}{c}\text { Conductivity } \\
{[\mathrm{S} / \mathrm{cm}]}\end{array}$ \\
\hline PB & PANI-BA & 1 & 1 & - & $2.8 \times 10^{-2}$ \\
PB@C5 & PANI-BA@\%5 MWCNT & 1 & 1 & $5 \%$ & $4.1 \times 10^{-2}$ \\
PB@C10 & PANI-BA@\%10 MWCNT & 1 & 1 & $10 \%$ & $8.7 \times 10^{-2}$ \\
PB@C15 & PANI-BA@\%15 MWCNT & 1 & 1 & $15 \%$ & $1.9 \times 10^{-1}$
\end{tabular}

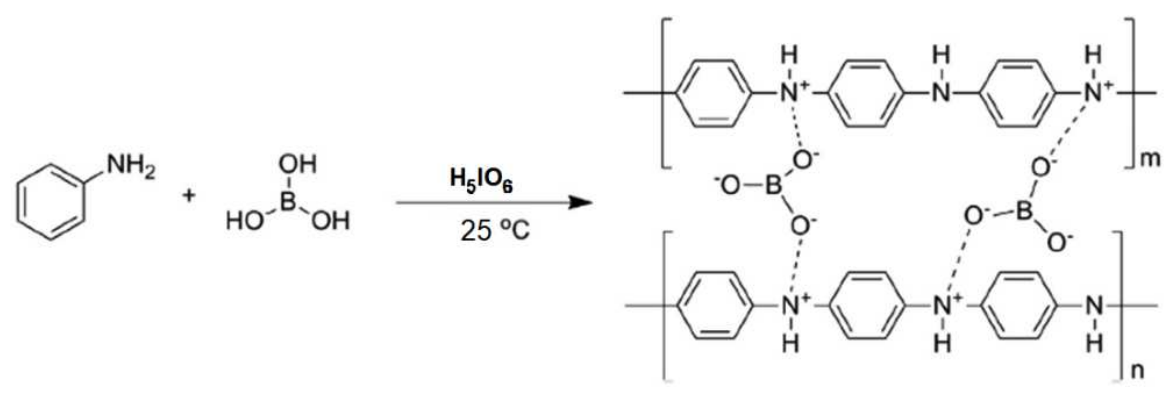

Fig. 1. Chemical polymerization of boric acid-doped aniline.

In this study, we report the production and characterization of a PANI-BA/MWCNT solar cell for the first time. We also investigate the surface morphology and structural properties of pure and MWCNT-doped PANI. A current-voltage analysis was used to determine the effect of the MWCNT contribution on DSSC performance. Various parameters of the prepared solar cells such as opencircuit voltage, short circuit current, filling factor, and efficiency were examined.

\section{Materials and methods}

\subsection{Materials}

In this study, boric acid-doped polyaniline (PANI-BA) was used as the main material. Aniline (Sigma) was distilled under a vacuum before use because it had a perishable structure in the air. For analytical purity, boric acid $\left(\mathrm{H}_{3} \mathrm{BO}_{3}\right)$ (Fluka) and periodic acid $\left(\mathrm{H}_{5} \mathrm{IO}_{6}\right)$ (Sigma) were used as supplied.

\subsection{Preparation of boric acid-doped/ multi-walled carbon nanotube (PANI-BA/MWCNT) composites}

The amount of $0.02 \mathrm{~mol}$ of aniline was dissolved in $1 \mathrm{M} \mathrm{H}_{3} \mathrm{BO}_{3}$ with stirring at room temperature for $30 \mathrm{~min}$. Then, $\mathrm{H}_{5} \mathrm{IO}_{6}$ dissolved in water was added dropwise to this solution medium so that $n_{\mathrm{H}_{5} \mathrm{IO}_{6}} / n_{\text {anilin }}=1: 1$. The mixture was maintained at room temperature with continuous stirring for $24 \mathrm{~h}$. The dark green product (PANI-BA) was then filtered and washed several times with distilled water and ethanol. The resulting solid product was dried under a vacuum at $60^{\circ} \mathrm{C}$. The synthesis mechanism is shown in Fig. 1.
The in situ chemical oxidative polymerization was selected to produce PANI-BA and multi-walled carbon nanotube (MWCNT) composites. As described, during the synthesis, 5\%, 10\%, and 15\% MWCNT were added to the medium at various weight percentages, respectively. The resulting reaction mixture was stirred at room temperature for $24 \mathrm{~h}$, then filtered and washed with distilled water and ethanol. The obtained (PANI-BA)/ MWCNT products were dried under vacuum at $60{ }^{\circ} \mathrm{C}$. Thus, MWCNT undoped (PB) and the different proportions of MWCNT-doped polymers (PB@C5, PB@C10, PB@C15) were obtained. Details are given in Table I.

\subsection{Preparation of PB, PB@C5, PB@C10, $\mathrm{PB} @ \mathrm{C} 15$, and Pt-based CEs}

The PB, PB@C5, PB@C10, and PB@C15 polymers were dissolved in formic acid at a certain concentration and then mixed with a magnetic stirrer for $2 \mathrm{~h}$. Before deposition, the fluorine-doped tin oxide (FTO) substrates (Asahi Glass; sheet resistance: $15 \Omega / \mathrm{cm}^{2}$ ) were cleaned as reported in our previous study [27]. After cleaning, a spin coating was carried out to deposit polymer solutions on FTO substrates for $30 \mathrm{~s}$ at $2000 \mathrm{r} / \mathrm{min}$. This process was repeated 15 times on each substrate to make the surface homogeneous. Lastly, PB, PB@C5, PB@C10, and PB@C15 catalyst-coated electrodes were annealed at $80^{\circ} \mathrm{C}$ for $45 \mathrm{~min}$. Otherwise, Pt-based $\mathrm{CE}$ (as reference) was prepared according to another study in [28].

\subsection{Characterization}

The ATR-FTIR spectroscopy was used for the chemical characterization of the obtained products. The surface morphology of the samples was 
examined using a TESCAN MAIA3 XMU scanning electron microscope (SEM). The X-ray diffraction spectra (XRD) of the polymers were examined by Rigaku Smartlab device with $\mathrm{CuK}_{\alpha}$ wavelength radiation beam at room temperature with $10^{\circ} \mathrm{C} \leq 2 \theta \leq 80^{\circ} \mathrm{C}$ limit values. Before DC conductivity measurements, dry pellets were prepared from a powdery polymer material under a pressure of 5 ton $/ \mathrm{cm}^{2}$. The dry conductivity values of polymers were measured by using a four-probe electrical conductivity measuring device (Entek Electronic) at room temperature. Gold-plate probes were used to avoid any errors caused by Ohmic contacts. The resistivity of the samples was measured at five different positions, and at least two pellets were measured for each sample: an average of 10 readings was used for conductivity calculations.

\section{Results and discussion}

\subsection{FTIR analysis of PANI-BA and MWCNT-doped PANI}

The FTIR spectra of PB, PB@C5, PB@C10, and $\mathrm{PB} @ \mathrm{C} 15$ were depicted in Fig. 2. Characteristic stretching bands of polyaniline $\mathrm{NH}$ $\left(3200 \mathrm{~cm}^{-1}\right)$, aliphatic $\mathrm{CH}\left(2935 \mathrm{~cm}^{-1}\right), \mathrm{C}-\mathrm{C}$ and $\mathrm{C}-\mathrm{N}\left(1740 \mathrm{~cm}^{-1}\right)$ and aromatic benzene $\left(807 \mathrm{~cm}^{-1}\right)$ bands were seen in PB. The PB@C5, PB@C10, and $\mathrm{PB} @ \mathrm{C} 15$ conductive polymers showed similar peaks around $3200 \mathrm{~cm}^{-1}$ due to the $\mathrm{N}-\mathrm{H}$ stretch. Also, $2909 \mathrm{~cm}^{-1}$ due to the aliphatic C-H stretch; at $1736-1680 \mathrm{~cm}^{-1}$, depending on the $\mathrm{C}-\mathrm{C}$ and $\mathrm{C}-\mathrm{N}$ stretching of the quinoid and benzenoid rings of polyaniline; peaks are seen as peaks similar to PB. There are several differences in the FTIR spectrum of pure PANI (PB) and MWCNT composites (PB@C5, $\mathrm{PB} @ \mathrm{C} 10$, and $\mathrm{PB} @ \mathrm{C} 15)$. In the MWNT/PANI composite spectrum, a peak around $1400 \mathrm{~cm}^{-1}$ is seen. The intensity of this peak increases with increasing rate of carbon nanotube doping. These data show that PANI in MWNT/PANI composites is richer in quinoid units than pure PANI [29, 30].

\subsection{Microstructure (SEM) analysis of PANI-BA and MWCNT-doped PANI}

Figure 3 shows the scanning electron micrographs of the polymer MWCNT-doped and undoped with boric acid polyaniline. Boric acid-doped polyaniline (PB) has a nonporous and clustered form (Fig. 3a). The figure shows the macroscopic and aggregated granular morphology. The particles are composed of particles of different sizes. SEM images of PB polymers with different amounts of carbon nanotubes are given in Fig. $3 \mathrm{~b}-\mathrm{d}$. It was determined that carbon nanotubes were placed in the polymer structure. Changes in the morphology of PB@C5, PB@C10, and PB@C15 can be attributed to the successful polymerization of aniline monomers due to increased MWCNT ratio. In another study in the

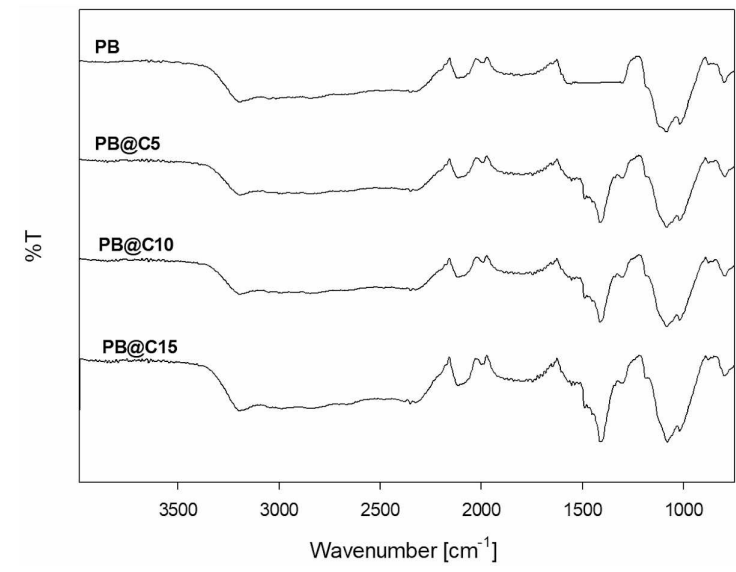

Fig. 2. FTIR spectra of PB, PB@C5, PB@C10, and $\mathrm{PB} @ \mathrm{C} 15$ polymers, respectively.
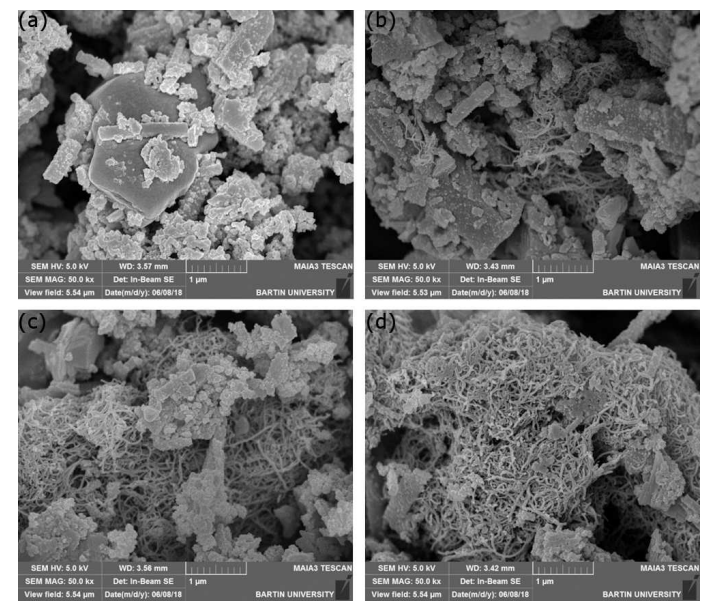

Fig. 3. SEM of the (a) PB, (b) PB@C5, (c) $\mathrm{PB} @ \mathrm{C} 10$ and $(\mathrm{d}) \mathrm{PB} @ \mathrm{C} 15$ polymers.

literature, similar changes in surface morphology were reported for physically crosslinked LaponitePANI composites [31]. Also, an increase in the MWCNT ratio can cause an increase in electrical conductivity as compared to $\mathrm{PB}$ and other polymers (PB@C5, PB@C10, and PB@C15).

\subsection{XRD analysis of PANI-BA and MWCNT-doped PANI}

The PB@C5, PB@C10 and PB@C15 polymers were dried under vacuum and then their XRD spectra were recorded in Fig. 4. The evaluation of the $\mathrm{XRD}$ results given for the dry $\mathrm{PB} @ \mathrm{C} 5, \mathrm{~PB} @ \mathrm{C} 10$, and PB@C15 systems shows the semicrystalline structure of the wide and dense band polymer given around $2 \theta=20^{\circ}$ in all composites. Moreover, it is seen that boric acid has changed its crystal structure when the XRD result is examined. The decline of the intensity at the peak of PANI as boric acid is added to the matrix is clearly visible and the amorphous structure of boric acid increases parallel to its concentration. The crystallinity of the structure increases with the addition of MWCNT. 


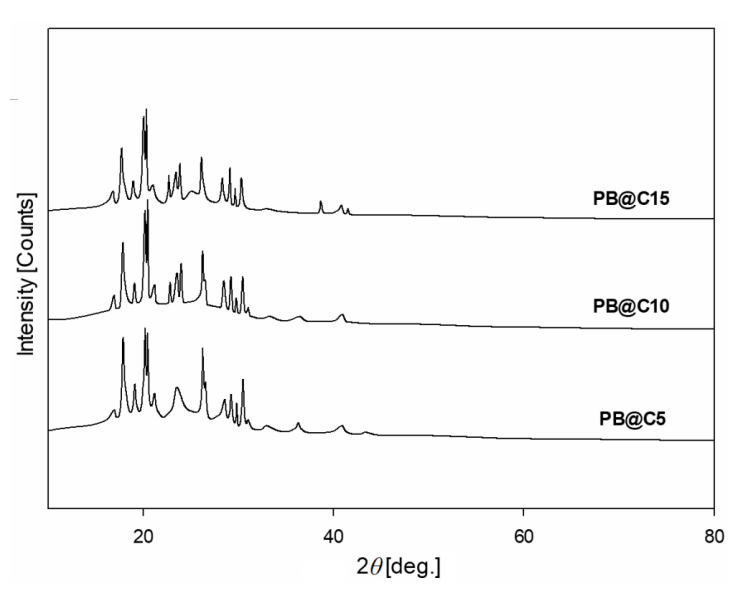

Fig. 4. X-ray diffractogram patterns of PB@C5, $\mathrm{PB} @ \mathrm{C} 10$, and $\mathrm{PB} @ \mathrm{C} 15$ polymers, respectively.

\subsection{Electrical conductivity properties of PANI-BA and MWCNT-doped PANI}

Dry pellets were prepared from the pulverized polymer material under a pressure of 5 tons $/ \mathrm{cm}^{2}$ before DC conductivity measurements. The conductivity values of the polymers were measured at room temperature using an electrical conductivity measuring device (Entek Electronic) with four probes. To prevent errors caused by Ohmic contacts, gold-plated probes were used. The resistivities of the polymers were obtained in five different locations and at least two pellets were measured for each sample: 10 readings averaged for conductivity calculations. The electrical conductivity values of PB, PB@C5, PB@C10, and PB@C15 were found as $2.8 \times 10^{-2}, 4.1 \times 10^{-2}, 8.7 \times 10^{-2}$, and $1.9 \times 10^{-1}$, respectively (Table I). It has been seen that conductivity values increase with the effect of MWCNT concentration.

\subsection{Photovoltaic performances of DSSCs}

Carbon nanotube additives are known to increase the performance characteristics of solar cells in conventional PANI applications. We calculated the typical photovoltaic cell values as open-circuit voltage $\left(V_{\mathrm{oc}}\right)$, short circuit current $\left(J_{\mathrm{sc}}\right)$, filling factor $(\mathrm{FF})$, and external photovoltaic efficiency $(\eta)$, which is the key parameter in evaluating the performance of solar cells.

\section{TABLE II}

Photovoltaic properties of DSSCs obtained by various CEs.

\begin{tabular}{l|c|c|c|c}
\hline \hline Samples & $V_{\text {oc }}$ & $J_{\text {sc }}$ & FF & $\eta[\%]$ \\
\hline PB & 0.47 & 3.47 & 0.41 & 0.69 \\
PB@C5 & 0.48 & 3.53 & 0.43 & 0.73 \\
PB@C10 & 0.51 & 4.91 & 0.46 & 1.15 \\
PB@C15 & 0.52 & 4.07 & 0.45 & 0.95
\end{tabular}

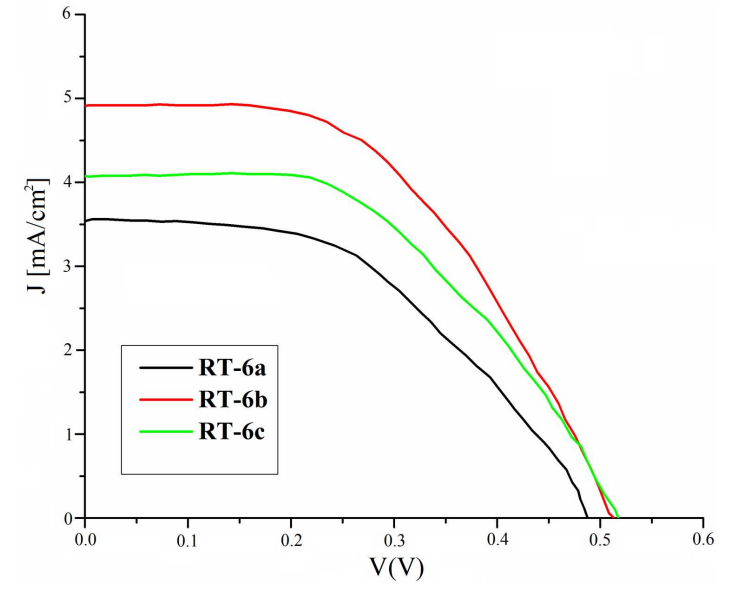

Fig. 5. The $J-V$ characteristics of DSSCs fabricated using various CEs.

The photocurrent density-voltage $(J-V)$ graphs of the prepared devices are given in Fig. 5 and the calculated photovoltaic parameters are summarized in Table II. The device with PB@C10 CE has produced $1.15 \%$ efficiency with $J_{\mathrm{sc}}=4.91 \mathrm{~mA} / \mathrm{cm}^{2}$, $V_{\mathrm{oc}}=0.51 \mathrm{~V}, \mathrm{FF}=0.46$. The efficiency of the solar cell using the MWCNT dopant was markedly higher than the PB polymer.

\section{Conclusions}

BA and MWCNT-doped conductive polymers were chemically synthesized and their structures were determined with various characterization techniques. We have produced a solar cell based on PANI-BA/MWCNT. The effect of the BA and MWCNT ratio on optical properties of PANI$\mathrm{BA} / \mathrm{MWCNT}$ has been studied in detail. It was observed that the electrical conductivity values increase when increasing the MWCNT ratio. Several photovoltaic parameters of the pure PANI and MWCNT-doped PANI solar cell have also been studied, such as open-circuit voltage $V_{\mathrm{oc}}$, shortcircuit current $J_{\mathrm{sc}}$, fill factor $\mathrm{FF}$, energy conversion efficiency $\eta$, etc., under solar simulator. MWCNTdoped PANI gave significantly high photocurrent voltages with reasonable efficiency as compared to the pure PANI. One can attribute this effect to the strong interaction between MWCNT-doped PANI and the FTO surface. The results of our studies highlight the feasibility/suitability of the lowcost optoelectronic devices, especially MWCNTdoped PANI grown on a suitable substrate using the chemical solution method for solar cells manufacturing.

\section{Acknowledgments}

This study was partly supported by Bartin University. 


\section{References}

[1] B.L. He, B. Dong, W. Wang, H.L. Li, Mater. Chem. Phys. 114, 371 (2009).

[2] F.D.R. Amado, M.A.S. Rodrigues, D.A. Bertuol, A.M. Bernardes, J.Z. Ferreira, C.A. Ferreira, J. Membr. Sci. 330, 227 (2009).

[3] X.X. Loh, M. Sairam, A. Bismarck, J.H.G. Steinke, A.G. Livingston, K. Li, J. Membr. Sci. 326, 635 (2009).

[4] M. Sairam, X.X. Loh, K. Li, A. Bismarck, J.H.G. Steinke, A.G. Livingston, J. Membr. Sci. 330, 166 (2009).

[5] M.A. Abshinova, N.E. Kazantseva, P. Saha, I. Sapurina, J. Kovarova, J. Stejskal, Polym. Degrad. Stabil. 93, 1826 (2008).

[6] J.M. Gustavsson, P.C. Innis, J. He, G.G. Wallace, D.E. Tallman, Electrochim. Acta 54, 1483 (2009).

[7] S. Radhakrishnan, N. Sonawane, C.R. Siju, Prog. Org. Coat. 64, 383 (2009).

[8] V. Erokhin, T. Berzina, M.P. Fontana, J. Appl. Phys. 97, 064501 (2005).

[9] K. Crowley, A. Morrin, A. Hernandez, E. O'Malley, P.G. Whitten, G.G. Wallace, M.R. Smyth, A.J. Killard, Talanta 77, 710 (2008).

[10] X.F. Yu, Y.X. Li, K. Kalantar-Zadeh, Sens. Actuators B Chem. 136, 1 (2009).

[11] A. Airoudj, D. Debarnot, B. Beche, F. Poncin-Epaillard, Talanta 77, 1590 (2009).

[12] Y.A. Ismail, S.R. Shin, K.M. Shin, S.G. Yoon, K. Shon, S.I. Kim, S.J. Kim, Sens. Actuators B Chem. 129, 834 (2008).

[13] H. Peng, L.J. Zhang, C. Soeller, J. TravasSejdic, Biomaterials 30, 2132 (2009).

[14] F. Cataldo, P. Maltese, Eur. Polym. J. 38, 1791 (2002).

[15] C.H. Chen, J. Appl. Polym. Sci. 89, 2142 (2003).

[16] P. Chandrasekhar, Conducting Polymers, Fundamentals and Applications: Including Carbon Nanotubes and Graphene, Springer International Publishing: Imprint: Springer, Cham 2018.
[17] S. Vadukumpully, J. Paul, N. Mahanta, S. Valiyaveettil, Carbon 49, 198 (2011).

[18] E.B. Sevinis, C. Sahin, M.E. Cinar, M.S. Eroglu, T. Ozturk, Polym. Eng. Sci. 56, 1390 (2016).

[19] O. Yagci, S.S. Yesilkaya, S.A. Yuksel, F. Ongul, N.M. Varal, M. Kus, S. Gunes, O. Icelli, Synth. Met. 212, 12 (2016).

[20] A. Subramanian, H.W. Wang, Appl. Surf. Sci. 258, 6479 (2012).

[21] S. Sonmezoglu, R. Tas, S. Akin, M. Can, Appl. Phys. Lett. 101, 253301 (2012).

[22] Y.H. Kim, M. Kim, S. Oh, H. Jung, Y. Kim, T.S. Yoon, Y.S. Kim, H.H. Lee, Appl. Phys. Lett. 100, 163301 (2012).

[23] S. Mangal, S. Adhikari, P. Banerji, Appl. Phys. Lett. 94, 223509 (2009).

[24] S. Bousalem, F.Z. Zeggai, H. Baltach, A. Benyoucef, Chem. Phys. Lett. 741, 137095 (2020).

[25] K. Kalanidhi, P. Nagaraaj, C.A. Aswathy, G.V. Sree, Chem. Phys. Lett. 739, 136929 (2020).

[26] G.T. Zhu, Q.P. Zhang, G.Z. Xie, Y.J. Su, K. Zhao, H.F. Du, Y.D. Jiang, Chem. Phys. Lett. 665, 147 (2016).

[27] R. Tas, M. Gulen, M. Can, S. Sonmezoglu, Synth. Met. 212, 75 (2016).

[28] S. Sonmezoglu, C. Akyurek, S. Akin, J. Phys. D: Appl. Phys. 45, 253301 (2012).

[29] D. Islam, M.H. Uddin, B. Pan, M.M.A. Joy, Chem. Phys. Lett. 760, 138007 (2020).

[30] L. Li, Z. Lou, W. Han, D. Chen, K. Jiang, G.Z. Shen, Adv. Mater. Technol. 2, 1600282 (2017).

[31] C.S. Jun, B. Sim, H.J. Choi, Colloids Surf. A 482, 670 (2015). 